\title{
Work in Progress: A Transferable Model to Improve Retention and Student Success in STEM through Undergraduate Research (NSF LEARN Consor- tium)
}

\section{Dr. Daniel Meeroff, Florida Atlantic University}

Daniel Meeroff is Professor and Associate Chair at Florida Atlantic University's Department of Civil, Environmental \& Geomatics Engineering. His area of specialization is Environmental Engineering, specifically water and wastewater engineering, water quality, solid and hazardous waste management, and pollution prevention. Dr. Meeroff is the founder and director of the Laboratories for Engineered Environmental Solutions (Lab.EES) (http: \\labees.civil.fau.edu). His Ph.D. in civil/environmental engineering was received from the University of Miami.

Dr. Meeroff was awarded the FAU Teaching Prize for Excellence in Undergraduate Education (2017), the FAU Distinguished Research Mentor of the Year (2015), the John J. Guarrera Engineering Educator of the Year for North America in 2014, and the FAU Distinguished Teacher of the Year in 2014 (as voted by the student body), which is the highest teaching honor at the university. In 2012, Dr. Meeroff and his colleague, Dr. Bloetscher, received the National Council of Examiners for Engineering and Surveying (NCEES) Award for Connecting Professional Practice and Education for their work on the Dania Beach Nanofiltration Facility, which is the first LEED-Gold water treatment facility in the world.

\section{Dr. Donna Chamely-Wiik, Florida Atlantic University}

Dr. Donna Chamely-Wiik is an Associate Scientist in the Department of Chemistry and Biochemistry, and Assistant Dean for Undergraduate Research at Florida Atlantic University. Her research interests include faculty and student involvement in undergraduate research, including an assessment of the impact of pedagogical interventions on student learning, development and perception.

\section{Dr. Kimberly R. Schneider, University of Central Florida}

Kimberly Schneider is the founding director of the Office of Undergraduate Research and also serves as the Assistant Dean within the Division of Teaching and Learning at the University of Central Florida. She has a B.S. from the University of Florida in Zoology and Ph.D. from the University of South Carolina in Biological Sciences. Her research interests are in marine ecology, science education, and high-impact learning practices.

Prof. William R. Kwochka, Western Carolina University

Dr. Evelyn Marques Frazier, Florida Atlantic University

Mr. Jordan Merritt, Florida Atlantic University

Mr. Michael Aldarondo-Jeffries, University of Central Florida

Dr. Alison I. Morrison-Shetlar, Western Carolina University 


\section{Work in Progress: A Transferable Model to Improve Retention and Student Success in STEM through Undergraduate Research (NSF LEARN ${ }^{\circledR}$ Consortium)}

This is a Work-In-Progress (WIP) paper describing the National Science Foundation (NSF) Learning Environment and Academic Research Network (LEARN ${ }^{\circledR}$ ) Consortium partnership, involving three different universities. The goal of the program is to adapt a model that was developed at one institution to determine if it is transferable to other student populations and institutions. The LEARN ${ }^{\circledR}$ model seeks to improve retention and student success measures in science, technology, engineering and math (STEM) students by successfully engaging them in the high impact practice of undergraduate research experience. The first version was developed by NSF funding at institution \#1, targeted for first time in college (FTIC) freshman (F-LEARN) [1]. With the success of this program, the model was implemented at institution \#2 and \#3, and a modified version was created for transfer students (T-LEARN) who have received their Associate degree and are enrolling in a STEM major at a four-year institution. The LEARN ${ }^{\circledR}$ program has three main pillars: 1) Academics/Research, which consists of a two-course, teamtaught introduction to research sequence, where the first course focuses on matching students to research faculty mentors and preparing students to successfully participate in research, and the second course builds upon the research skills foundation from the introductory course to further develop a research proposal, while working in a research group with a faculty, and often graduate student, mentor; 2) Mentoring, which consists of a multi-tiered approach designed to support the students with trained peer mentors often former LEARN ${ }^{\circledR}$ participants assigned to each student in the program, paired laboratory/faculty mentors, and a LEARN ${ }^{\circledR}$ program coordinator; and 3) Community Building, which consists of living/learning opportunities, social programming, and other non-research related extracurricular activities. It is hypothesized that the LEARN $^{\circledR}$ program participants will:

1. Demonstrate higher fall-to-fall retention, credits earned, GPA, and graduation rates compared to matched intra-institutional comparison groups;

2. Demonstrate developmental gains in critical thinking and oral/written communication skills during the LEARN ${ }^{\circledR}$ program;

3. Report satisfactory experiences and added value to student learning as a direct result of participation.

\section{Selection of LEARN ${ }^{\circledR}$ student participants}

Each year starting in the fall semester, cohorts of F-LEARN and T-LEARN students are accepted at each of the three institutions. F-LEARN candidates enter directly from high school (FTIC) with a declared major in a STEM field in pursuit of a BS degree. T-LEARN candidates enter directly from a 2-year institution where they earned an Associate degree prior to the university start date. T-LEARN students must also have a declared major in a STEM field in pursuit of a BS degree with a minimum transfer GPA of 3.0 or above. The 2-semester LEARN ${ }^{\circledR}$ program starts in the fall and runs through the end of the spring term. Peer mentors are selected at each institution, from previous participants whenever possible, and each participant is assigned to a peer mentor for the year. The LEARN ${ }^{\circledR}$ program is managed by a coordinator and the NSF Principal Investigators at each institution. During the fall term, LEARN ${ }^{\circledR}$ students are matched with a laboratory research mentor or depending on the institution, seek their own mentor. The F- 
LEARN students are matched for research group shadowing and research apprenticeships [2]. TLEARN students are matched for directed independent research. Not all students that start LEARN $^{\circledR}$ end up completing all components of the program. A summary of program participants within the LEARN ${ }^{\circledR}$ program at all three institutions is found in Table 1 .

Table 1. Characteristics of LEARN ${ }^{\circledR}$ program participants

\begin{tabular}{|l|r|r|r|r|r|r|}
\hline \multirow{2}{*}{ Type of Participant } & \multicolumn{2}{|c|}{ Institution 1 } & \multicolumn{2}{c|}{ Institution 2 } & \multicolumn{2}{c|}{ Institution 3 } \\
\cline { 2 - 7 } & $\mathbf{2 0 1 7 - 1 8}$ & $\mathbf{2 0 1 8 - 1 9}$ & $\mathbf{2 0 1 7 - 1 8}$ & $\mathbf{2 0 1 8 - 1 9}$ & $\mathbf{2 0 1 7 - 1 8}$ & $\mathbf{2 0 1 8 - 1 9}$ \\
\hline Number of Peer Mentors & 6 & 7 & 6 & 5 & 4 & 4 \\
\hline $\begin{array}{l}\text { Number of Participating } \\
\text { Laboratory Research Mentors }\end{array}$ & 35 & 37 & 20 & 16 & 20 & 19 \\
\hline Number of F-LEARN Students & 28 & 35 & 11 & 14 & 20 & 9 \\
\hline $\begin{array}{l}\text { Percent Underrepresented } \\
\text { Minorities }\end{array}$ & $64 \%$ & $57 \%$ & $62 \%$ & $57 \%$ & $20 \%$ & $10 \%$ \\
\hline Percent Female & $44 \%$ & $43 \%$ & $83 \%$ & $57 \%$ & $50 \%$ & $30 \%$ \\
\hline Number of T-LEARN Students & 22 & 23 & 15 & 10 & 13 & 11 \\
\hline $\begin{array}{l}\text { Percent Underrepresented } \\
\text { Minorities }\end{array}$ & $77 \%$ & $40 \%$ & $79 \%$ & $70 \%$ & $5 \%$ & $30 \%$ \\
\hline Percent Female & $68 \%$ & $60 \%$ & $60 \%$ & $60 \%$ & $54 \%$ & $50 \%$ \\
\hline
\end{tabular}

\section{Matched intra-institutional comparison control group}

At the start of each fall term, the entire population of enrolled undergraduates in STEM disciplines at each institution is identified from official student tables to determine a comparison group. The census data subset is based on the following factors: 1) entry status into the university is the same as the paired F/T-LEARN cohort (FTIC students only for F-LEARN comparison group, transfer students only for T-LEARN comparison group); 2) first academic term of enrollment is similar to the paired F/T-LEARN cohort; 3) declared as STEM in their first term (see Appendix A for a list of CIP codes that map to STEM majors for this project); 4) have not participated in another Living-Learning Community or other Enriching Learning Experience (e.g. honors in the major, National Merit Scholars, mentoring programs, etc.); and 5) have a cumulative GPA similar to the F/T-LEARN cohort (high school GPA for FTIC; previous institution GPA for transfer students), which was done by computing the minimum and maximum high school GPA or previous institution GPA for the F/T-LEARN cohort and removing any students from the population who have GPAs outside this range. From this population, a stratified sample of approximately 100 students or more is selected to represent the comparison group for each particular cohort year, one for the F-LEARN cohort (FTIC students) and the other for the T-LEARN cohort (transfer students). Factors used to implement stratified sampling included: 1 ) gender (two categories; $\mathrm{M}=$ male; $\mathrm{F}=$ female); 2) ethnicity (four categories; $\mathrm{W}=$ White; $\mathrm{B}=$ Black; $\mathrm{H}=$ Hispanic; $\mathrm{O}=$ Other); and 3) high school GPA/previous institution GPA indicator (two categories; below or above the median value). Each year of the program, there were variations within each institution's ability to establish a comparison group that met all the variables within the stratified sampling, but the protocol used was the same for each institution.

\section{Program assessment}

Formative and summative assessment instruments will be used to evaluate and assess both product and process to provide assessment results within and between institutions and by cohort 
type (F-LEARN and T-LEARN). The assessment plan will use a mixed-method approach [3] to assess the effectiveness in fulfilling the desired learning outcomes, which are:

1. Fall-to-fall retention, credits earned, GPA, and graduation rates of LEARN ${ }^{\circledR}$ cohorts will be higher when compared to matched intra-institutional comparison control groups

2. Students in the program will show developmental gains in critical thinking and oral/written communication skills using a pre-post methodology. Included are results from the Criticalthinking and Assessment Test (CAT) and assessment (using a rubric) of embedded measures of student learning outcomes in writing assignments each semester (pre- and post-)

3. Students in the program will report satisfactory experiences and added value to their learning as a consequence of participation in the $\operatorname{LEARN}^{\circledR}$ community including research coursework, mentoring, and community building as measured with surveys of perception and focus groups

1. Fall-to-fall retention, course credits attempted and earned, GPA, and graduation rates In collaboration with each institutions' office of assessment, data was gathered for both the experimental and comparison group on the following parameters: 1) Fall-to-fall retention is defined by students who registered to take classes the following fall semester upon completing participation in the LEARN ${ }^{\circledR}$ program, and retention at the university and retention in STEM are tracked; 2) Course credits attempted (excluding university withdrawal students) and course credits earned for the term specified are tracked; 3) Term GPA (institution credits) and cumulative GPA (institution credits) for the term specified are tracked.; 4) Percent graduation in 4 and 6 years for F-LEARN and percent graduation in 2 and 3 years for T-LEARN are tracked.

\section{Developmental gains}

To evaluate critical thinking skills, two instruments are used, the Critical-thinking Assessment Test (CAT), developed at Tennessee Technical University with support from the National Science Foundation [4], and an embedded measures assessment of student learning rubric, modified from a published rubric [5,6]. The CAT instrument is administered in a pre-/post design during the Fall/Spring terms for each cohort in accordance with an approved IRB protocol for human studies. The pre-test is taken by all enrolled LEARN ${ }^{\circledR}$ students within the first few weeks of the Fall semester, and the post-test is administered at the end of the following Spring semester. Differences between pre- and post- scores are statistically analyzed using a two-tailed, paired student's t-test.

The embedded measures assessments of student learning outcomes for LEARN ${ }^{\circledR}$ participants are administered by each institution in the study in a pre-/post design for the Fall and Spring terms of the Introduction to Research two-course sequence. Efforts were made to standardize the delivery, the scaffolding of student learning, and the implementation timeline of assignments at all three institutions. The pre-assignment is given on or around week 8 of the Fall semester, and the postassignment is collected at the end of the Spring semester. The pre-assignment is a research synthesis writing assignment in which students dissect two primary source articles from within one research area. Students summarize their articles by analyzing whether the reported results align with the conclusions made in each article. They are also asked to determine whether the methodology is sound and what additional research questions are evoked. The post-assignment during the following Spring semester builds on the pre-assignment by asking students to compose a literature review and background with a minimum of 5 references for F-LEARN and 
10 for T-LEARN. Each of these assignments is graded by a standard rubric (Appendix B). Targeted Student Learning Outcomes (SLO) measured include Content Knowledge, Formulate Question, Critical Thinking, and Communication. Each SLO is evaluated at three levels: Exemplary, Competent and Developing. Written student works are collected by each institution and assessed by two independent, normed evaluators. A randomly identified sample $(\sim 50 \%)$ is selected and evaluated among the three institutions' pre-assessments. Analysis of pre- and postassessments are conducted as well as calculation of growth scores (post-assessment scores minus pre-assessment scores). Only matched pairs are included in the calculations for the growth scores.

\section{Surveys of perception and focus groups}

To evaluate student perceptions of the program, student feedback is collected with attitudinal surveys and focus groups annually. The intent is to gather information from the students regarding continuous improvement of the program and to make changes as appropriate prior to the next course or iteration of the cohort. A one-year later survey is administered to program completers in May by the external assessment team for two consecutive years. The results of this survey are intended to help the program coordinators understand what opportunities the LEARN $^{\circledR}$ students are involved in after they complete the program (e.g., continuation in oncampus research, internships, leadership, etc.). Additionally, some of the consortium institutions are informally tracking the activities of the LEARN ${ }^{\circledR}$ students as they graduate from the program, including participation in summer research fellowships, internal institutional opportunities such as honors programs and funded grants, as well as post-graduation activities.

\section{Preliminary results}

The major findings for the first full year of the program that started in Fall 2016 show that students participating in LEARN ${ }^{\circledR}$ demonstrate improvements in critical thinking, credits earned, and retention characteristics, while maintaining similar grade point averages when compared to the comparison group [7]. Statistical analyses are currently underway. As we refine our curriculum and practices in the classroom, along with the management of the laboratory experiences and mentor training, it is anticipated that even greater improvements in the student success measures presented above will be achieved. Furthermore, continuous improvement efforts after each cohort are demonstrating how the LEARN ${ }^{\circledR}$ model can be established and made transferable across multiple unique institutions, while still maintaining consistency of the core program elements.

\section{Acknowledgements}

This material is based upon work supported by the National Science Foundation under Grant No. 1524666, 1524601, and 1524607. Any opinions, findings and conclusions or recommendations expressed in this material are those of the author(s) and do not necessarily reflect the views of the National Science Foundation. 


\section{References}

1. K. Schneider, A. Bickel, and A Morrison-Shetlar, "Planning and implementing a comprehensive student-centered research program for first-year STEM undergraduates," Journal of College Science Teaching, vol. 44, no. 3, pp. 37-43, 2015.

2. K. Schneider and A. Bickel, "Undergraduate research apprenticeship model: graduate students matched with STEM first-year mentees,” Council on Undergraduate Research Quarterly, vol. 36, no. 1, pp. 25-31, 2015.

3. J. Frechtling. “The 2002 user-friendly handbook for project evaluation,” National Science Foundation, Arlington, VA, Directorate for Education and Human Resources, NSF-02-057 2002.

4. B. Stein and A. Haynes, "Engaging faculty in the assessment and improvement of students' critical thinking using the critical thinking assessment test," Change: The Magazine of Higher Learning, vol. 43, no. 2, pp. 44-49, 2011.

5. D. Chamely-Wiik, M. Holman, P. Kirsch, D. Meeroff, and J. Peluso, "Scaffolding the development of student research skills for capstone experiences: A multi-disciplinary approach,” Council of Undergraduate Research Quarterly, vol. 34, no. 4, pp. 18-25, 2014.

6. http://www.fau.edu/ouri/Distinction\%20Through\%20Discovery\%20Student\%20Achievemen t\%20Fall\%202015b.docx [Accessed Jan. 25, 2019].

7. K Schneider, D. Chamely-Wiik, D. Meeroff, E. Frazier, W. Kwochka, A. Morrison-Shetlar, unpublished data.

\section{Appendix A}

Any academic program with CIP code beginning in "02", "03", "11", "14", "15", "26", "27", "40" are defined as STEM

Appendix B

\begin{tabular}{|c|c|c|c|}
\hline SLO Indicators & Exemplary & Competent & Developing \\
\hline $\begin{array}{l}\text { SLO1. } \\
\text { Knowledge - } \\
\text { Theoretical } \\
\text { Framework }\end{array}$ & $\begin{array}{l}\text { A. Fully identifies the key } \\
\text { background information of } \\
\text { the research topic that } \\
\text { contributes to the } \\
\text { hypothesis/research } \\
\text { objective } \\
\text { B. Cites the appropriate } \\
\text { number of references in } \\
\text { APA style } \\
\text { C. Logically describes how } \\
\text { each reference contributes } \\
\text { to a greater understanding } \\
\text { of the subject in an } \\
\text { appropriate sequence }\end{array}$ & $\begin{array}{l}\text { A. Identifies some of the key } \\
\text { background information of } \\
\text { the research topic that } \\
\text { contributes to the } \\
\text { hypothesis/research } \\
\text { objective } \\
\text { B. Does not cite an } \\
\text { appropriate number of } \\
\text { references or does not use } \\
\text { the APA style consistently } \\
\text { C. Minimally organizes } \\
\text { references in a logical } \\
\text { manner and somewhat } \\
\text { describes how each } \\
\text { reference contributes to a } \\
\text { greater understanding of } \\
\text { the subject }\end{array}$ & $\begin{array}{l}\text { A. Minimally identifies the } \\
\text { key background } \\
\text { information of the } \\
\text { research topic } \\
\text { B. Uses inappropriate } \\
\text { references and/or an } \\
\text { insufficient number of } \\
\text { appropriate references } \\
\text { and does not use the APA } \\
\text { style consistently } \\
\text { C. Does not organize } \\
\text { references in a logical } \\
\text { manner and does not } \\
\text { describe how each } \\
\text { reference is related to a } \\
\text { greater understanding of } \\
\text { the subject }\end{array}$ \\
\hline
\end{tabular}




\begin{tabular}{|c|c|c|c|}
\hline SLO Indicators & Exemplary & Competent & Developing \\
\hline $\begin{array}{l}\text { SLO2. } \\
\text { Formulate } \\
\text { Questions - } \\
\text { Rationale }\end{array}$ & $\begin{array}{l}\text { A. Clearly articulates the } \\
\text { research question(s) by } \\
\text { providing well-defined } \\
\text { hypotheses/objectives for } \\
\text { each question asked } \\
\text { B. Identifies and explains a } \\
\text { clear "Gap in Knowledge" } \\
\text { C. The rationale for exploring } \\
\text { the question is embedded } \\
\text { in a clear, professional } \\
\text { context that integrates } \\
\text { evidence }\end{array}$ & $\begin{array}{l}\text { A. Partially articulates the } \\
\text { research question(s) by } \\
\text { providing weak } \\
\text { hypotheses/objectives } \\
\text { that need improvement } \\
\text { B. Minimally } \\
\text { identifies/explains the } \\
\text { "Gap in Knowledge"; some } \\
\text { questions remain for the } \\
\text { reader } \\
\text { C. The rationale for exploring } \\
\text { the question is generally } \\
\text { embedded within a } \\
\text { professional context, but } \\
\text { some questions remain for } \\
\text { the reader }\end{array}$ & $\begin{array}{l}\text { A. Does not an articulate the } \\
\text { research question or does } \\
\text { not provide appropriate } \\
\text { hypotheses/research } \\
\text { objectives that are } \\
\text { testable } \\
\text { B. Does not identify/explain } \\
\text { the "Gap in Knowledge"; } \\
\text { many questions remain for } \\
\text { the reader } \\
\text { C. The rationale for exploring } \\
\text { the question is incomplete }\end{array}$ \\
\hline $\begin{array}{l}\text { SLO3. Critical } \\
\text { Thinking - } \\
\text { Analysis }\end{array}$ & $\begin{array}{l}\text { A. Accurately relates the data } \\
\text { and findings in the } \\
\text { references to the research } \\
\text { question(s) being pursued } \\
\text { B. Thoroughly evaluates } \\
\text { information while } \\
\text { acknowledging limits and } \\
\text { synthesizing competing } \\
\text { points of view } \\
\text { C. Clearly discusses broader } \\
\text { impacts and significance of } \\
\text { the research }\end{array}$ & $\begin{array}{l}\text { A. Relates some data and } \\
\text { findings to the research } \\
\text { question(s) being pursued; } \\
\text { some questions remain for } \\
\text { the reader } \\
\text { B. Sufficiently evaluates } \\
\text { information, while } \\
\text { acknowledging some limits } \\
\text { or synthesizing competing } \\
\text { points of view, but some } \\
\text { questions remain for the } \\
\text { reader } \\
\text { C. Minimally discusses } \\
\text { broader impacts and } \\
\text { significance of the } \\
\text { research }\end{array}$ & $\begin{array}{l}\text { A. Does not relate data and } \\
\text { findings to the research } \\
\text { question(s) being pursued; } \\
\text { uses generalizations or } \\
\text { inaccuracies } \\
\text { B. Minimally evaluates } \\
\text { information, while not } \\
\text { acknowledging limits or } \\
\text { competing points of view } \\
\text { C. No mention of broader } \\
\text { impacts or significance of } \\
\text { the research }\end{array}$ \\
\hline $\begin{array}{l}\text { SLO4. } \\
\text { Communication- } \\
\text { Format Level }\end{array}$ & $\begin{array}{l}\text { A. Fully follows the correct } \\
\text { formatting, without error } \\
\text { B. Presented at an } \\
\text { appropriate level, targets } \\
\text { the correct audience, and } \\
\text { uses professional tone } \\
\text { without spelling, } \\
\text { sentence-level or } \\
\text { grammatical errors } \\
\text { C. Provides appropriate and } \\
\text { consistent in-text citation } \\
\text { for references AND a } \\
\text { separate reference section } \\
\text { in APA format }\end{array}$ & $\begin{array}{l}\text { A. Generally follows the } \\
\text { correct formatting with } \\
\text { only a few minor errors } \\
\text { B. Generally presented at an } \\
\text { appropriate level, targets } \\
\text { the correct audience, and } \\
\text { uses professional tone } \\
\text { with only few spelling, } \\
\text { sentence-level or } \\
\text { grammatical errors } \\
\text { C. Generally provides } \\
\text { appropriate and consistent } \\
\text { in-text citation for } \\
\text { references AND a separate } \\
\text { reference section in APA } \\
\text { format with only a few } \\
\text { errors }\end{array}$ & $\begin{array}{l}\text { A. Formatting is incorrect, } \\
\text { irrelevant, or } \\
\text { inappropriate } \\
\text { B. Targets the wrong level(s) } \\
\text { or audience; or uses an } \\
\text { unprofessional tone with } \\
\text { numerous spelling, } \\
\text { sentence-level or } \\
\text { grammatical errors making } \\
\text { it hard to read } \\
\text { C. Provides citations that are } \\
\text { incomplete, inappropriate } \\
\text { or incorrectly formatted, } \\
\text { or a separate reference } \\
\text { section is missing }\end{array}$ \\
\hline
\end{tabular}

